\title{
Prescribing in Schizophrenia / Psychosis: Increasing Polypharmacy Over Time
}

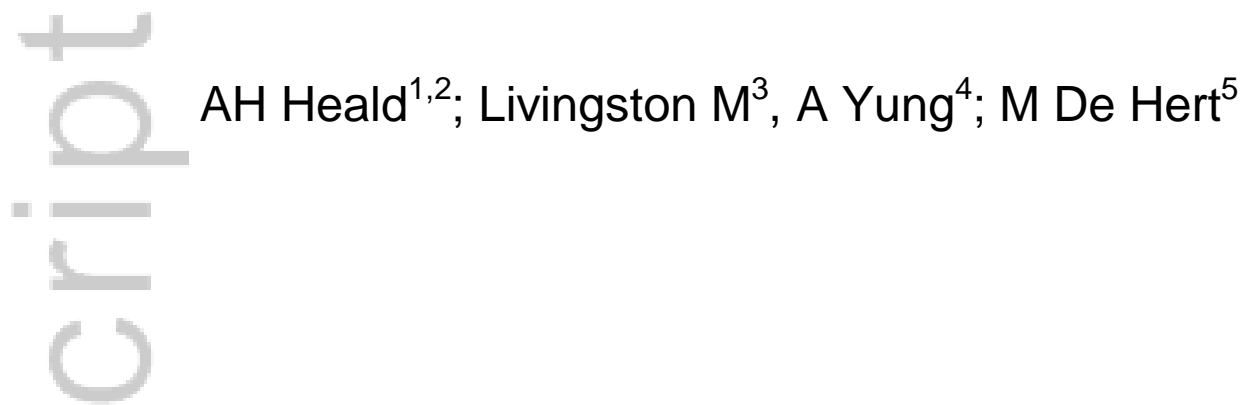

over time

Running Title: Prescribing in Psychosis: increase in polypharmacy $\longrightarrow$

${ }^{1}$ School of Medicine and Manchester Academic Health Sciences

Centre, University of Manchester, Manchester; ${ }^{2}$ Department of Medicine, Leighton Hospital, Crewe;

${ }^{3}$ Department of Blood Sciences, Walsall Manor Hospital, Walsall; ${ }^{4}$ Institute of Brain, Behaviour and Mental Health University of Manchester Oxford Road Manchester; ${ }^{5}$ University Psychiatric Center campus Kortenberg, Katholieke Universiteit Leuven, Leuvense Steenweg 517, 3070 Kortenberg, Belgium;

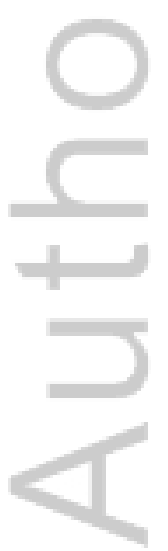

This is the author manuscript accepted for publication and has undergone full peer review but has not been through the copyediting, typesetting, pagination and proofreading process, which may lead to differences between this version and the Version of Record. Please cite this article as doi: $10.1002 /$ hup. 2579

This article is protected by copyright. All rights reserved. 
Keywords: Psychotropic, prescribing, schizophrenia, psychosis, BMI

Word Count excluding abstract: 1338

\begin{abstract}
Introduction

Diabetes, obesity and metabolic syndrome are highly prevalent in patients with Severe Mental IIIness (SMI). Psychotropic polypharmacy is becoming increasingly prevalent within the UK. We determined the change in the number of psychotropic medications prescribed over time and trends in weight and fasting blood glucose.
\end{abstract}

\title{
Methods
}

195 individuals with Schizophrenia / Psychosis on the SMI Register in Cheshire, UK were followed up between 2004 and 2012. Individuals were identified through a semi-anonymised search of GP registers.

\section{Results}

The total number of different medications prescribed increased from 140 in 2004 to 226 in 2012 with the mean number of medication groups per patient increasing from 0.71 to $1.15(p<0.001)$. The number of individuals on no medication reduced from $58.0 \%$ to $33.3 \%$ (OR $0.3695 \% \mathrm{Cl} 0.24-0.54$ ) and 
those prescribed one medication increased from 20.5\% to 31.8\% (OR 1.93 $95 \%$ Cl 1.22-3.06).

Baseline BMI was 28.9, increasing to 30.8 at 8 year follow-up, $(F$ 6.5, $p=0.003$ ) with a significant corresponding increase in fasting blood glucose.

\section{Conclusion}

In conclusion, we determined an increase in psychotropic polypharmacy over the follow-up period. BMl/fasting blood glucose increased over time. Clozapine and Depot antipsychotic prescriptions were often not recorded in the GP records.

This article is protected by copyright. All rights reserved. 


\section{Introduction}

The main aim of the treatment of schizophrenia and other Severe Enduring Mental Illnesses (SMI) is to control active symptoms and to enable patients to live as normal lives as possible. However metabolic abnormalities are commonly associated with treatment and include: weight gain, impaired glycaemia, the development of type 2 diabetes, reduced HDL cholesterol, raised LDL cholesterol and raised triglyceride levels (Heald et al, 2016; Holt et al, 2010).

Currently prescribed psychotropics (antipsychotics, antidepressants, and mood stabilizers) may cause $2-17$

kgNorfswatight ga0B). Early weight gain in the weeks after treatment initiation is often a predictor of long term weight gain (Allison et al, 1999) It has been known for a long time now that there is a difference between the antipsychotic agents in their predisposition to cause weight gain. The dibenzodiazepines, Olanzapine and Clozapine are the most likely agents to cause weight gain (Briffa \& Mehan, 1998). They continue to be prescribed widely across the world and in the case of Clozapine, it remains the medication of choice for many people with treatment resistant schizophrenia.

Greater understanding of how in a real world setting prescribing of agents may influence weight change is important. In one area of the UK (Cheshire), 
general practice (GP) SMI registers were used to determine the relation of prescribing with change in weight and rates of dysglycaemia over time.

\section{Methods}

We used the Severe Enduring Mental Illness (SMI) Register in Central and Eastern Cheshire, UK to identify patients with schizophrenia or a schizophrenia related condition, with prescribing of all CNS medication determined for the years 2004 and 2012. In total 262 patients with a schizophrenia related condition were identified. The study was approved by our local ethics committee and has not been submitted elsewhere.

Analysis was restricted to those who were eligible in both years excluding those without a recorded diagnosis in the first year and those who had died by 2012. This left a total of 195 individuals in the analysis. For all included patients we calculated the number of CNS medications prescribed in the first 84 days of both years. This gives similar results to other methods (Fincke et al, 2005).

We counted the presence of distinct medication groups by dividing prescriptions into five medication groups (antidepressants, antipsychotics, benzodiazepine/hypnotics, mood stabilizer, other CNS medications) and calculated the number of medication groups dispensed in each other. 
The statistical significance of any differences between 2004 and 2012 were evaluated, using directly age-sex standardised proportions for 2012 to account for the ageing of the population between 2004 and 2012. We also calculated the levels of prescribing for all possible medication group combinations for each year.

The physical health screen involved height and weight measurement with calculation of body mass index (BMI) (weight $(\mathrm{kg}) /$ height $^{2}$ (meters)) and a blood test for fasting glucose.

\section{Statistics}

Data analysis was performed using IBM SPSS Statistics for Windows, Version 21.0. Armonk, NY: IBM Corp. Non-normally distributed data were log transformed prior to statistical analysis. Odds ratios were calculated comparing the proportions of patients on medication at two different time points 2004 and 2012.

\section{Results}

Total number of medications prescribed: We found that the overall number of different medications prescribed increased from 140 in 2004 to 226 in 2012 
(Table 1) with the mean number of medication groups per person increasing from 0.71 to $1.15(p<0.001)$. The number of individuals on no medication reduced from $58.0 \%$ to $33.3 \%$ (OR $0.3695 \% \mathrm{Cl} 0.24-0.54$ ) and those prescribed one medication increased from $20.5 \%$ to $31.8 \%$ (OR $1.9395 \% \mathrm{Cl}$ 1.22-3.06). No other significant differences were found.

The specific medications vs numbers of people taking them in 2004 and 2012 are shown in Table 2 for all psychotropic medications. Depot antipsychotic medication and Clozapine were excluded because many of these prescriptions were not issued in primary care. The table reflects the changes in prescribing in the UK and the rest of Europe over the intervening years.

We suspect that a number of the people seemingly on no medication were taking secondary care prescribed Clozapine or were receiving depot medication, again prescribed by primary care and not recorded in the GP record.

Individual medication prescriptions: For those individuals prescribed one medication group only, a significant increase was found for anti-depressants (OR $8.095 \% \mathrm{Cl}$ 1.1-65.2). For the two medication group, the number prescribed combination anti-depressant and antipsychotic increased from $1.2 \%$ to $5.4 \%$ OR $1.2-24.1$. No significant difference in the individual medication combinations for those prescribed three or four medication combinations was noted. 
Hospital prescribed medication: Only a small number of patients were recorded in the primary care record as being prescribed Clozapine as most Clozapine prescribing is carried out by secondary care and not recorded in the GP record. This was also apparent for prescribing of depot antipsychotic medication which is often administered in community mental health centres (CMHTs).

Metabolic trends: Baseline BMI for the participants was 28.9 (normal range 18.5-25.0), increasing to 30.8 at 8 year follow-up, $(F 6.5, p=0.003)$. Over the 8 year follow-up period, there was a significant increase in fasting blood glucose from $5.45 \mathrm{mmol} / \mathrm{L}$ to $5.82 \mathrm{mmol} / \mathrm{L}(\mathrm{F} 3.6, \mathrm{p}=0.008)$. Fasting blood glucose also increased slightly with age at baseline $(p=0.028)$.

\section{Discussion}

In our study, there was a significant increase in polypharmacy over the years of follow-up, which occurred in parallel with an increase in BMI. This finding is in keeping with others who have reported a reduction in monotherapy from $48 \%$ in 1980 to $20 \%$ in studies carried out between 1991 and 2000 (Rittmannsberger, 2002). From the baseline medication data reported in the CATIE (Clinical Antipsychotic Trails of Intervention Effectiveness) study, rates of polypharmacy were also high with: $6 \%$ taking two antipsychotics and 38\% 
taking combination antipsychotic and antidepressant (Chakos et al, 2006). Reasons for the increasing prevalence of psychotropic polypharmacy are multifactorial and include: increased numbers of available medications, widespread prescribing of psychotropics within primary care, decision to augment with additional medication in the face of ongoing symptoms and at times a prescriber reluctance to withdraw existing medication (Hoffman et al, 2011).

Given the established association between Clozapine and weight gain and the development of dysglycaemia (Anderson et al, 2015) and the link between the older depot preparations and extrapyramidal side effects (Lammers et al, 2013), any oral antipsychotic or depot antipsychotic preparations not prescribed in primary care, need to be recorded in the GP prescribing record. All GP systems have the facility to include medications not prescribed in primary care and this facility should be utilized for accurate medicines reconciliation. A strength of this study is that we were able to see all medications prescribed by the GP in the time frame examined.

\section{Limitations}

It is likely that rates of polypharmacy are underreported in this cohort, largely because Clozapine and depot antipsychotic medication, which are often prescribed by secondary care, may not be recorded within the primary care 
record. Furthermore we have not included those patients who were alive in 2004 but had died by 2012. Given data from previous studies (eg Osborne 2008 et al, 2008) would propose that a higher proportion of these than average were on polypharmacy at baseline.

We were not able to take account of adherence to psychotropic or change in diet. Finally it is likely individuals in the background population would show some weight increase over the same period of time.

While it is recognised that at times polypharmacy is necessary, it is important for clinicians to review all prescribed medication in a timely fashion, in order to ensure that medications are prescribed in a rationalized way.

In conclusion, in this UK based cohort study, we showed that there is an increase in polypharmacy in patients with schizophrenia and other psychoses over time. This is associated with a tendency to weight gain and to a higher chance of dysglycaemia. GP records should include all medication that the patient is receiving not just that prescribed by the GP to enable a full understanding of factors predisposing to cardiometabolic risk when physical health checks are performed. This is an important message from this paper relating to a phenomenon that could be addressed quite easily. 
Conflicts of interest: None to declare

Funding: Not applicable

Ethical approval: Informed consent obtained

Disclosures: None to declare

Acknowledgements: To ${ }^{\circledR}$ EMIS Health for support in data collection

\section{References}

Anderson SG, Livingston M, Couchman L, Smith DJ, Connolly M, Miller J, Flanagan RJ, Heald AH. Sex differences in plasma clozapine and norclozapine concentrations in clinical practice and in relation to body mass index and plasma glucose concentrations: a retrospective survey. Annals of general psychiatry. 2015; 14:39

Allison DB, Fontaine KR, Moonseong $\mathrm{H}$, Mentore JL, Cappelleri JC, Chandler LP, et al. The distribution of Body Mass Index among Individuals with and without Schizophrenia. J Clin Psychiatry 1999; 60: 215-220 
Briffa D, Meehan T. Weight changes during clozapine treatment. Australian and New Zealand Journal of Psychiatry. 1998; 32: 718-721

Chakos MH, Glick ID, Miller AL, Hamner MB, Miller DD, Patel JK, et al. Baseline use of concomitant psychotropic medications to treat schizophrenia in the CATIE trial. Psychiatr Serv. 2006; 57:1094-101

Fincke B, Snyder K, Cantillon C, Gaehde S, Standring P, Fiore L et al. Three complementary definitions of polypharmacy: methods, application and comparison of findings in a large prescription database. Pharmacoepidemiol Drug Saf. 2005; 14: 21-28

Heald AH, Martin JL, Payton T, Khalid L, Anderson SG, Narayanan RP, De Hert M, Yung A, Livingston M. Changes in metabolic parameters in patients with severe mental illness over a 10-year period: A retrospective cohort study. Aust N Z J Psychiatry. 2016 Jan 14. pii: 0004867415625817. [Epub ahead of print] accessed 9 April 2016

Hoffman DA, Schiller J, Greenblatte JM, Iosifescu DV. Polypharmacy or medication washout: an old tool revisited Neuropsychiatr Dis Treat. 2011; 7: $639-648$

This article is protected by copyright. All rights reserved. 
Holt RI, Abdelrahman T, Hirsch M, Dhesi Z, George T, Blincoe T, Peveler RC. The prevalence of undiagnosed metabolic abnormalities in people with serious mental illness. J Psychopharmacol. 2010; 24: 867-73

Lammers L, Zehm B, Williams R. Risperidone long-acting injection in Schizophrenia Spectrum Illnesses compared to first generation depot antipsychotics in an outpatient setting in Canada. BMC psychiatry. 2013 May $30 ; 13: 155$

Nasrallah H.A. Review of the effect of atypical antipsychotics on weight. Psycho-neuroendocrinology. 2003; 28: 83-96

Osborne DPJ, Levy G, Nazareth I et al. Relative risk of cardiovascular and cancer mortality in people with severe enduring mental illness from the United Kingdom's General Practice Research database. Arch Gen Psychiatry 2007; 64: $242-249$

This article is protected by copyright. All rights reserved. 
Table 1. Prescribing total by medication group comparison for 2004/2012

\begin{tabular}{|l|c|c|c|}
\hline & $\begin{array}{c}\text { Overall } \\
(2004) \\
\text { Number (mean) }\end{array}$ & $\begin{array}{c}\text { Overall } \\
(2012) \\
\text { Number } \\
(\text { mean) }\end{array}$ & $\begin{array}{r}\text { Difference } \\
2004 / 2012 \\
(95 \% \mathrm{Cl})\end{array}$ \\
\hline $\begin{array}{l}\text { Total medications } \\
\text { prescribed }\end{array}$ & $140(0.71)$ & $226(1.15)$ & $86(\mathrm{p}<0.001)$ \\
\hline No medication & $\begin{array}{c}\text { Overall } \\
(2004)\end{array}$ & $\begin{array}{c}\text { Overall } \\
(2012) \\
\text { Number }(\%)\end{array}$ & $\begin{array}{l}\text { Age standardised } \\
\text { Odds Ratio }\end{array}$ \\
\hline 1 medication group & $113(58.0)$ & $65(33.3)$ & $0.36(0.24-0.54)$ \\
\hline 2 medications group & $40(20.5)$ & $65(31.8)$ & $1.93(1.22-3.06)$ \\
\hline 3 medications group & $29(14.9)$ & $44(22.6)$ & $1.66(0.99-2.80)$ \\
\hline
\end{tabular}

This article is protected by copyright. All rights reserved. 
Table 2: Medication prescribed (number of patients receiving it) by individual agent in 2004 and 2012 (excluding depot medication and Clozapine)

\begin{tabular}{|c|c|c|c|c|}
\hline Medication & $\begin{array}{c}2004 \\
\text { (number } \\
\text { prescribed) }\end{array}$ & $\begin{array}{c}2012 \text { (number } \\
\text { prescribed) }\end{array}$ & Change & Change (\%) \\
\hline Ariprazole & 3 & 29 & +26 & +867 \\
\hline Amisulpiride & 9 & 34 & +25 & +278 \\
\hline Chlorpromazine & 39 & 21 & -18 & -46 \\
\hline Clopixol tablets & 3 & 18 & +15 & +500 \\
\hline Clozapine & excluded & excluded & & \\
\hline Haloperidol & 12 & 14 & +2 & +17 \\
\hline $\begin{array}{l}\text { Levo- } \\
\text { mepromazine }\end{array}$ & 4 & 0 & -4 & -100 \\
\hline Olanzapine & 102 & 99 & -3 & -2.9 \\
\hline Pimozide & 1 & 0 & -1 & -100 \\
\hline Promazine & 10 & 7 & -3 & -30 \\
\hline Quetiapine & 50 & 66 & +16 & +32 \\
\hline $\begin{array}{c}\text { Risperidone } \\
\text { tablets }\end{array}$ & 48 & 46 & -2 & -4 \\
\hline Sulpiride & 6 & 4 & -2 & -33 \\
\hline Thioridazine & 9 & 0 & -9 & -100 \\
\hline Trifluoperazine & 31 & 22 & -9 & -29 \\
\hline Carbamazepine & 38 & 23 & -15 & -39 \\
\hline Depakote & 16 & 53 & +37 & +231 \\
\hline Gabapentin & 3 & 7 & +4 & +133 \\
\hline Lamotrigine & 20 & 20 & 0 & 0 \\
\hline Levetiracetam & 4 & 5 & +1 & +25 \\
\hline Lithium & 99 & 87 & -12 & -12 \\
\hline Topiramate & 3 & 0 & -3 & -100 \\
\hline Valproate & 33 & 33 & 0 & 0 \\
\hline
\end{tabular}




\begin{tabular}{|c|c|c|c|c|}
\hline Amitriptyline & 12 & 15 & +3 & +25 \\
\hline Atomoxetine & 3 & 3 & 0 & 0 \\
\hline Citalopram & 50 & 70 & +20 & +40 \\
\hline Clomipramine & 22 & 15 & -7 & -32 \\
\hline Dosulepin & 7 & 6 & -1 & -14 \\
\hline Doxepin & 7 & 2 & -5 & -71 \\
\hline Duloxetine & 0 & 13 & & New drug \\
\hline Excitalopram & 0 & 22 & & New Drug \\
\hline Fluoxetine & 27 & 13 & -14 & -52 \\
\hline Fluvoxamine & 2 & 1 & -1 & -50 \\
\hline Imipramine & 3 & 3 & 0 & 0 \\
\hline Lofepramine & 9 & 5 & -4 & -44 \\
\hline Mirtazapine & 24 & 22 & -2 & -8 \\
\hline Moclobemide & 1 & 0 & -1 & -100 \\
\hline Nortryptiline & 1 & 3 & +2 & +200 \\
\hline Paroxetine & 43 & 18 & -25 & -58 \\
\hline Prothiaden & 11 & 0 & -11 & $-100 \%$ \\
\hline Reboxetine & 3 & 2 & +1 & +33 \\
\hline Sertraline & 18 & 20 & +2 & +11 \\
\hline Trazodone & 12 & 5 & -7 & -58 \\
\hline Trimipramine & 2 & 0 & -2 & $-100 \%$ \\
\hline Venlafaxine & 76 & 58 & -18 & -24 \\
\hline & & & & \\
\hline Alprazolam & 3 & 3 & 0 & 0 \\
\hline Buspirone & 1 & 3 & +2 & +200 \\
\hline Chlordiazepoxide & 4 & 1 & -3 & -75 \\
\hline Clonazepam & 4 & 9 & +5 & +125 \\
\hline Diazepam & 53 & 32 & -21 & -39 \\
\hline Escitalopram & 6 & 22 & +16 & +267 \\
\hline $\begin{array}{c}\text { Flupenthixol } \\
\text { tablets }\end{array}$ & 10 & 6 & -4 & -40 \\
\hline Lorazepam & 7 & 2 & -5 & -71 \\
\hline Lormetazepam & 1 & 0 & -1 & $-100 \%$ \\
\hline Nitrazepam & 6 & 3 & -3 & -50 \\
\hline Oxazepam & 2 & 1 & -1 & -50 \\
\hline Temazepam & 5 & 7 & +2 & +40 \\
\hline Zimovane & 4 & 3 & -1 & -25 \\
\hline Zolpidem & 6 & 21 & +15 & +250 \\
\hline Zopiclone & 42 & 42 & 0 & 0 \\
\hline
\end{tabular}

This article is protected by copyright. All rights reserved. 


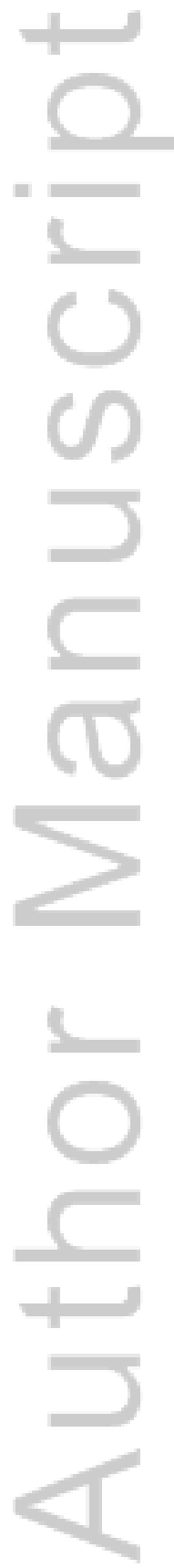

This article is protected by copyright. All rights reserved. 


\section{Adrian Heald}

Corresponding author

adrian.heald@manchester.ac.uk

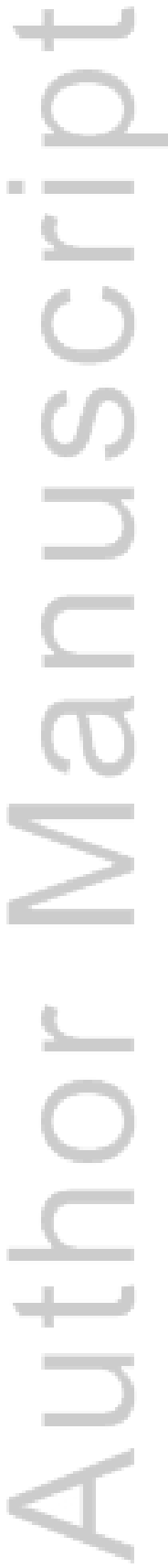

This article is protected by copyright. All rights reserved. 


\section{University Library}

\section{- M M I N E R VA A gateway to Melbourne's research publications}

Minerva Access is the Institutional Repository of The University of Melbourne

Author/s:

Heald, A;Livingston, M;Yung, A;De Hert, MA

Title:

Prescribing in schizophrenia and psychosis: Increasing polypharmacy over time

Date:

2017-03-01

Citation:

Heald, A., Livingston, M., Yung, A. \& De Hert, M. A. (2017). Prescribing in schizophrenia and psychosis: Increasing polypharmacy over time. HUMAN PSYCHOPHARMACOLOGYCLINICAL AND EXPERIMENTAL, 32 (2), https://doi.org/10.1002/hup.2579.

Persistent Link:

http://hdl.handle.net/11343/292557 